\title{
3D CONCRETE PRINTING IN THE SERVICE OF LEAN CONSTRUCTION
}

\author{
Fatima El Sakka ${ }^{1}$, Farook Hamzeh ${ }^{2}$
}

\begin{abstract}
: with the current conventional construction practices, the application of lean thinking is deemed challenging. Yet the introduction of 3D printing to the construction industry seems to bolster the lean philosophy goals. The literature, however, has not yet sufficiently addressed the correlation between 3D concrete printing and lean construction. Thus, this research aims at uncovering the complementary relationship between the two. The study is based on mapping the value stream of the construction process of a residential house using data extracted from an actual project. Value stream mapping is conducted for both methods of construction, the conventional method and 3D concrete printing. Comparing the value stream maps revealed a $60 \%$ reduction in the production lead time. Further analysis unveiled reduction in construction cost, especially labour cost, minimization of different types of waste as well as improvement of quality. Such achievements satisfy the essential goals of a lean process including higher quality, lower cost, and shorter lead time.
\end{abstract}

Keywords: Lean construction, 3D concrete printing, traditional construction, value stream mapping

\section{INTRODUCTION}

Since its introduction into the construction industry, the lean ideal, which consists of giving customers what they want "instantly" and without waste (Liker 2004), seemed to be very far from realization. Approaching such a goal could be made possible by adopting various lean tools and principles in construction. Minimizing various types of waste including waiting, defective work, unnecessary movements or transport, and others (Liker 2004) can reduce construction cost and duration. Other lean tools such as Jidoka (i.e. stopping the work to fix quality problems), standardization of tasks, and use of visual control (Liker 2004) can improve work quality and, thus, increase value.

Nevertheless, traditional methods used in building a house cannot fully satisfy a customer interested in a sophisticated architecture due to the increased complexity and augmented cost of building the corresponding formworks. Also, the completion time of a simple housing construction project would span around 6 months on average (Edge 2000). Thus, delivering maximum value to the customer in terms of fast construction and minimum waste remains difficult to fulfil using traditional construction methods. Yet a real breakthrough with respect to this occurred when 3D concrete printing technology was introduced to the construction industry.

1 Master's Student, Civil and Environmental Engineering Department, American University of Beirut, Beirut, Lebanon, fbe04@mail.aub.edu

2 Assistant Professor, Civil and Environmental Engineering, American University of Beirut, Lebanon, +961350000 Ext 3616, fax: + 611 744462, Farook.Hamzeh@aub.edu.lb 
Contour crafting, a construction automation technique, was first introduced by Behrokh Khoshnevis in the mid 1990's (Bos 2016). It is an additive manufacturing technique based on layered fabrication that is applicable to the construction of large structures. To transform a 3D model to a built structure, this technology employs computer control to create smooth and accurate planar subsequent layers of extruded materials (Khoshnevis 2004). It produces smooth surface layers by delineating the extruded materials using vertical and horizontal trowels (Hwang and Khoshnevis 2005). It is worth mentioning that a wide research has been focused on the materials that could be considered for 3D printing. Such materials comprise a variety of possible constituents including concrete, bioplastic, construction waste, steel, gypsum, and others (Labonnote et al. 2016). Other studies investigate the requirements that the mix design should meet including extrudability, buildability, adhesiveness, and strength (Malaeb et al. 2015).

At a time when quality of work is low, labour efficiency is low, site accident rate is high, and construction control is complex, 3D concrete printing appears as a revolutionary technology in construction (Khoshnevis 2004). In fact, remarkable and promising contributions by the technology has been already proven in a study conducted on 3D buildings that were printed in China (Feng 2014): (1) it is $(+10) \times$ faster than traditional construction, (2) it has a low cost since a few construction workers are needed, no formworks are required, and structure optimization to save materials is possible, (3) it allows to easily print high-cost curved buildings and sophisticated architectures that are hard and, sometimes, impossible to build in other ways, and others. In actuality, 30\%-60\% of savings in construction waste, $50 \%-70 \%$ reduction in production time, and $50 \%-80 \%$ cut in labour cost could be recorded (Whirlwind Team 2016). Such achievements greatly support the three pillars of the lean ideal; time, cost, and value.

Moreover, 3D concrete printing has the potential to greatly contribute to achieving various lean principles in construction. Work by Rouhana et al (2014) highlighted some contributions of 3D concrete printing that relate to lean principles including quality at bay, waste, standardization and continuous improvement, and target costing. However, in spite of this strong correlation between 3D concrete printing and lean philosophy, no other similar research has yet been conducted. Such a correlation could be illustrated using value stream mapping. A value stream map (VSM) allows a visual representation of material and information flows throughout a production process (Rother and Shook 2003). It provides a "door-to-door" analogy which reveals how transitions occur among various processes (El Sakka et al. 2016).

Thus, the aim of this paper is to elaborately show how 3D concrete printing complements the lean philosophy. The study is based on drawing the VSM's of the construction process of a residential house using both methods, the traditional method and 3D concrete printing. Finally, the maps are studied and compared from a lean perspective, and the lean benefits of using 3D concrete printing are pinpointed.

\section{Methodology}

In order to attain the goal of this research, a definite methodology was followed. First, a literature review was conducted to explore the various contributions 3D concrete printing has helped realize in the construction industry. An actual building project was then used to collect data on production rates necessary for mapping the value streams. Based on this data, VSM's were drawn for the construction process of a residential house assuming similar phases of slab-on-grade construction for both methods. A value stream 
subsumes all the value adding as well as non-value adding actions necessary to bring a product from concept to delivery (Lean Lexicon 2003).

A floor plan drawn using Autodesk Homestyler software, illustrated in Error! Reference source not found.-a below, is adopted throughout the study. The footprint is $100 \mathrm{~m}^{2}(10 \mathrm{~m} \times 10 \mathrm{~m})$ with a total walls length of $60 \mathrm{~m}$, a wall thickness of $20 \mathrm{~cm}$ (Refer to Figure 1-b), and a clear height of $3 \mathrm{~m}$. It is divided into four square rooms $(5 \mathrm{~m} \times 5 \mathrm{~m})$ with one exterior and three interior $2 \mathrm{~m} \times 0.9 \mathrm{~m}$ doors and four $0.8 \mathrm{~m} \times 1.2 \mathrm{~m}$ windows.
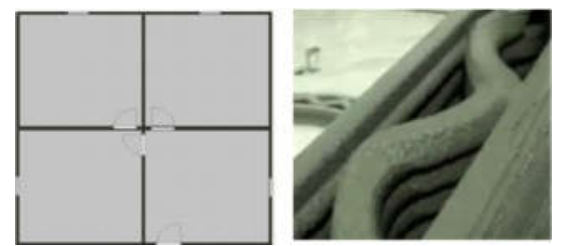

Figure 1. a- Floor Plan / b- Wall Section Layout (Hewitt 2010)

In the conventional method and for simplification purposes, all the walls, interior and exterior walls, are considered to be made of reinforced concrete. As for the 3D concrete printing technique, all the walls are post tensioned. For a sound comparison, in both types of construction, the roof is made of precast pre-slabs overlaid with $10 \mathrm{~cm}$ of concrete top slab.

For the traditional house construction, production values corresponding to different stages of construction are taken from an actual project. As for the 3D concrete printing technology, durations are computed based on an assumed nozzle speed of $15 \mathrm{~cm} / \mathrm{sec}$ that matches the literature values. It should be noted that such a speed is contingent on many factors including the set up and the operation of the 3D printer.

For the conventional method, the unit of flow used for drawing the VSM is $5 \mathrm{~m} \times 3 \mathrm{~m}$ of surface area (i.e. equivalent to a wall) for the construction of vertical elements and $5 \mathrm{~m}$ $\times 5 \mathrm{~m}$ of surface area (i.e. equivalent to a room's roof) for the construction of horizontal elements. For 3D concrete printing, selecting a single realistic unit of flow is more problematic since the building process does not have a cyclic nature. Thus, the unit of flow is considered only a function of surface area for now and is later clarified.

\section{CONVENTIONAL CONSTRUCTION}

Production rates needed for mapping the value streams are mainly taken from the case study project. The data is summarized in Table 1 below.

Table 1. Production Rates

\begin{tabular}{ccccccc}
\hline Task & $\begin{array}{c}\text { Rebar } \\
\text { Installation }\end{array}$ & $\begin{array}{c}\text { Formwork } \\
\text { installation }\end{array}$ & $\begin{array}{c}\text { Walls } \\
\text { Concreting }\end{array}$ & $\begin{array}{c}\text { Formwork } \\
\text { Removal }\end{array}$ & $\begin{array}{c}\text { Precast } \\
\text { Installation }\end{array}$ & $\begin{array}{c}\text { Slab } \\
\text { Concreting }\end{array}$ \\
\hline $\begin{array}{c}\text { Production } \\
\text { Rate }\end{array}$ & 0.03 & 1.4 & 2.5 & 0.35 & 0.12 & 1.75 \\
& MANHR/ & MANHR/ & MANHR/ & MANHR/ & MANHR/ & MANHR/ \\
& $1 \mathrm{~kg}$ & $\mathrm{~m}^{2}$ & $\mathrm{~m}^{3}$ & $\mathrm{~m}^{2}$ & $\mathrm{~m}^{2}$ & $\mathrm{~m}^{3}$ \\
\hline
\end{tabular}

The following calculations and assumptions are necessary for drawing the VSM.

- The total formwork area excluding doors and windows is

$$
60 \times 3-4 \times 2 \times 0.9-4 \times 1.2 \times 0.8=169 \mathrm{~m}^{2}
$$


- The quantity of vertical and horizontal reinforcement is computed based on the minimum requirements for concrete walls rebar. The minimum requirement is \#4 steel bar with a maximum separation of 4 inches (American PolySteel, 2005). In this study, a total number of 66 vertical bars distributed along the perimeter and 3 horizontal bars along each wall are installed. The unit weight of a \#4 steel bar is $0.996 \mathrm{~kg} / \mathrm{m}$. Thus, the total weight of reinforcement is approximately $0.996 \mathrm{~kg} /$ $\mathrm{m} \times(66 \times 3 \mathrm{~m}+3 \times 60 \mathrm{~m})=377 \mathrm{~kg}$.

The total number of hours needed to install all the bars is $377 \mathrm{~kg} \times$ $0.03 \mathrm{MANHR} / \mathrm{kg}=11.3 \mathrm{MANHR}$.

The equivalent production rate would then be $11.3 M A N H R \div 169 \mathrm{~m}^{2}=$ $0.067 \mathrm{MANHR} / \mathrm{m}^{2}$.

- The production rate for concrete in MANHR $/ m^{2}$ is

$$
2.5 \mathrm{MANHR} / \mathrm{m}^{\wedge} 3 \times 0.2 \mathrm{~m}=0.5 \mathrm{MANHR} / \mathrm{m}^{\wedge} 2
$$

- It is assumed that there are 1 steel fixer and 1 labourer for rebar installation, 2 carpenters and 2 labourers for formwork installation, 4 labourers for concreting, 1 carpenter and 1 labourer for formwork removal, and 1 skilled and 2 unskilled labourers for precast slabs installation. Accordingly, each rate is divided by its corresponding number of workers to be used in cycle time calculation.

- Vertical formworks are removed after 1 day after installation and roof installation starts after all the vertical elements are finished. The available working time is 8 hours per day, and construction proceeds continuously without any disruptions due to unforeseen or any other conditions.

- In a manufacturing process, lead time corresponding to inventory between different stages is determined by dividing the inventory quantity by the customer demand per day. In this study, the time for which inventory is waiting without any processing is more a function of the production rate of the subsequent process because the authors have assumed minimal overproduction between the stations. Hence, the inventory between stations is kept to a minimum.

The VSM for the conventional construction process of the house is displayed in Figure 2.

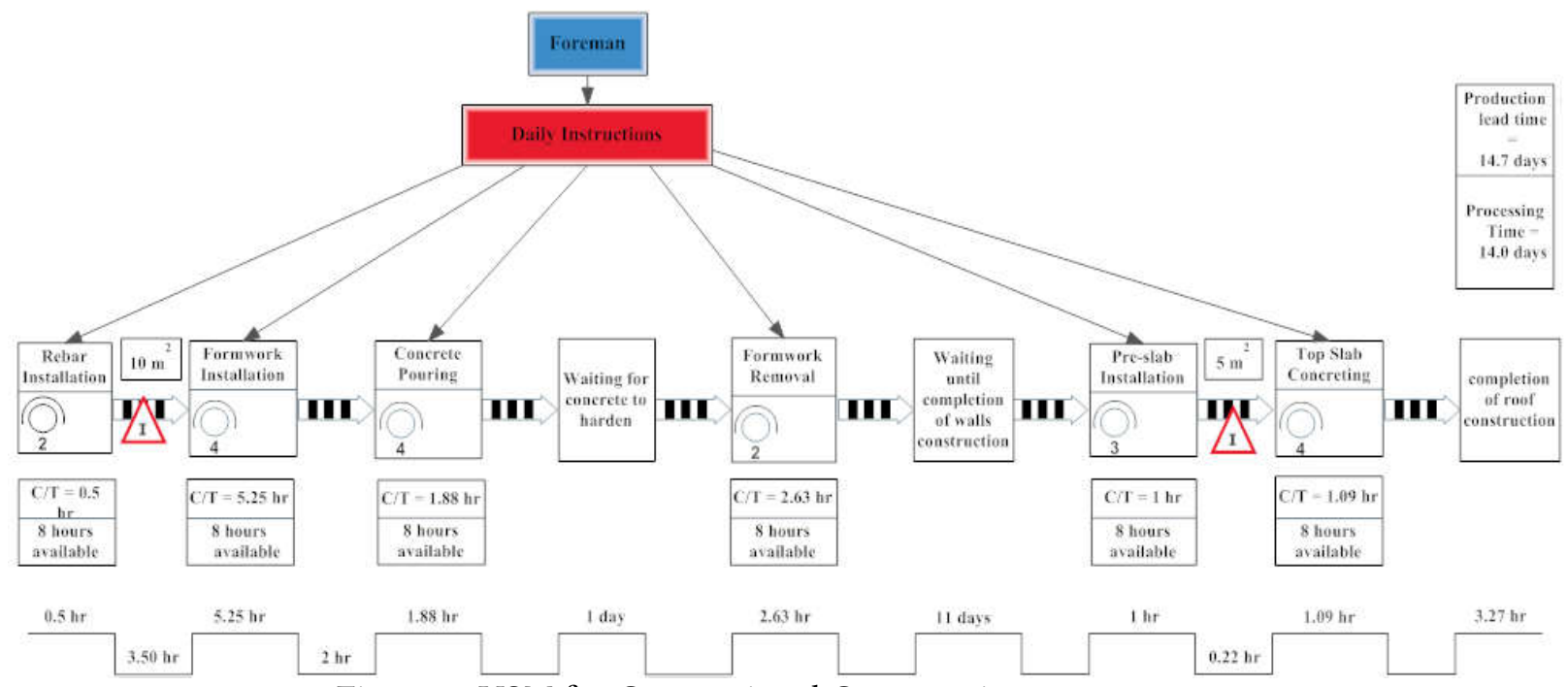

Figure 2. VSM for Conventional Construction 


\section{3D CONCRETE PRINTING}

With a speed of $15 \mathrm{~cm} / \mathrm{sec}$, the printer takes $6.67 \mathrm{mins}$ to deposit concrete layersalong the whole perimeter of $60 \mathrm{~m}$. Each layer is considered to have a depth of $5 \mathrm{~cm}$ and a filament width of $5 \mathrm{~cm}$. The printer is directed not to deposit concrete at the locations of doors and windows.

Based on this information, the production rate of concrete printing is $(6.67$ mins $) /(60 \mathrm{~m} \times 0.05 \mathrm{~m})=2.22$ mins per $1 \mathrm{~m}^{2}$ of vertical surface area

The printing process is divided into multiple stages as doors and windows impose modifying the commands fed into the printer. The first stage consists of printing concrete layers up to the bottom of the windows, a total surface area of $1.2 \mathrm{~m} \times 60 \mathrm{~m}=$ $72 \mathrm{~m}^{2}$. Note that the widths of the doors were not subtracted from the total perimeter since the printer has to cross over them anyway. In the second stage, layers are printed up to the top of the windows which is designed to be aligned with the top of the doors in this study. This corresponds to a total area of $0.8 \mathrm{~m} \times 60 \mathrm{~m}=48 \mathrm{~m}^{2}$. This is followed by the installation of 8 precast lintels above windows and doors, a stage for which about 30 mins are allocated. The third stage comprises completing the printing process of the walls. This is equivalent to an area of $1 \mathrm{~m} \times 60 \mathrm{~m}=60 \mathrm{~m}^{2}$.

The concrete is left for three days to harden before post-tensioning is done. Tendons are to be placed every $6 \mathrm{~m}$ along the perimeter of the house. Thus, a total of 11 ducts are installed at equally spaced intervals of $6 \mathrm{~m}$. Half an hour is allocated for installing and tensioning tendons in each duct and, thus, a total of $11 \times 0.5=5.5 \mathrm{hr}$ are required for completion. This duration is converted to mins $/ \mathrm{m}^{2}$ to be used in the VSM as follows:

$$
(5.5 \mathrm{hr} \times 60 \mathrm{mins} / \mathrm{hr}) /(3 \mathrm{~m} \times 60 \mathrm{~m})=1.83 \mathrm{mins} / \mathrm{m}^{2}
$$

Post tensioning the tendons is followed by grouting the space left in the hole in order to establish a bond between the duct and the printed concrete. This could be easily done using the printer and can be completed within a few minutes. Yet a production rate of 5 mins/duct is used and is converted as follows:

$$
(5 \mathrm{mins} / \text { duct } \times 11 \text { ducts }) /\left(180 \mathrm{~m}^{2}\right)=0.306 \mathrm{mins} / \mathrm{m}^{2}
$$

Note that the unit of flow for these two stages is the tributary area corresponding to each duct, an area of $6 m \times 3 m=18 \mathrm{~m}^{2}$. Laying concrete over pre-slabs consists of printing $2 \times(10 \mathrm{~m} \div 0.05 \mathrm{~m})=400$ filaments that are $10 \mathrm{~m}$ long. These are equivalent to a total length of $4000 \mathrm{~m}$ of which printing necessitates $(4000 \mathrm{~m} \div 0.15 \mathrm{~m} / \mathrm{sec}) \div$ $(3600 \mathrm{sec} / \mathrm{hr})=7.41 \mathrm{hr}$. Thus, the relevant production rate is $(7.41 \mathrm{hr} \times 60 \mathrm{mins} /$ $h r) \div 100 \mathrm{~m}^{2}=4.44 \mathrm{mins} / \mathrm{m}^{2}$.

The VSM for the construction process using 3D printing is represented in Figure 3. 


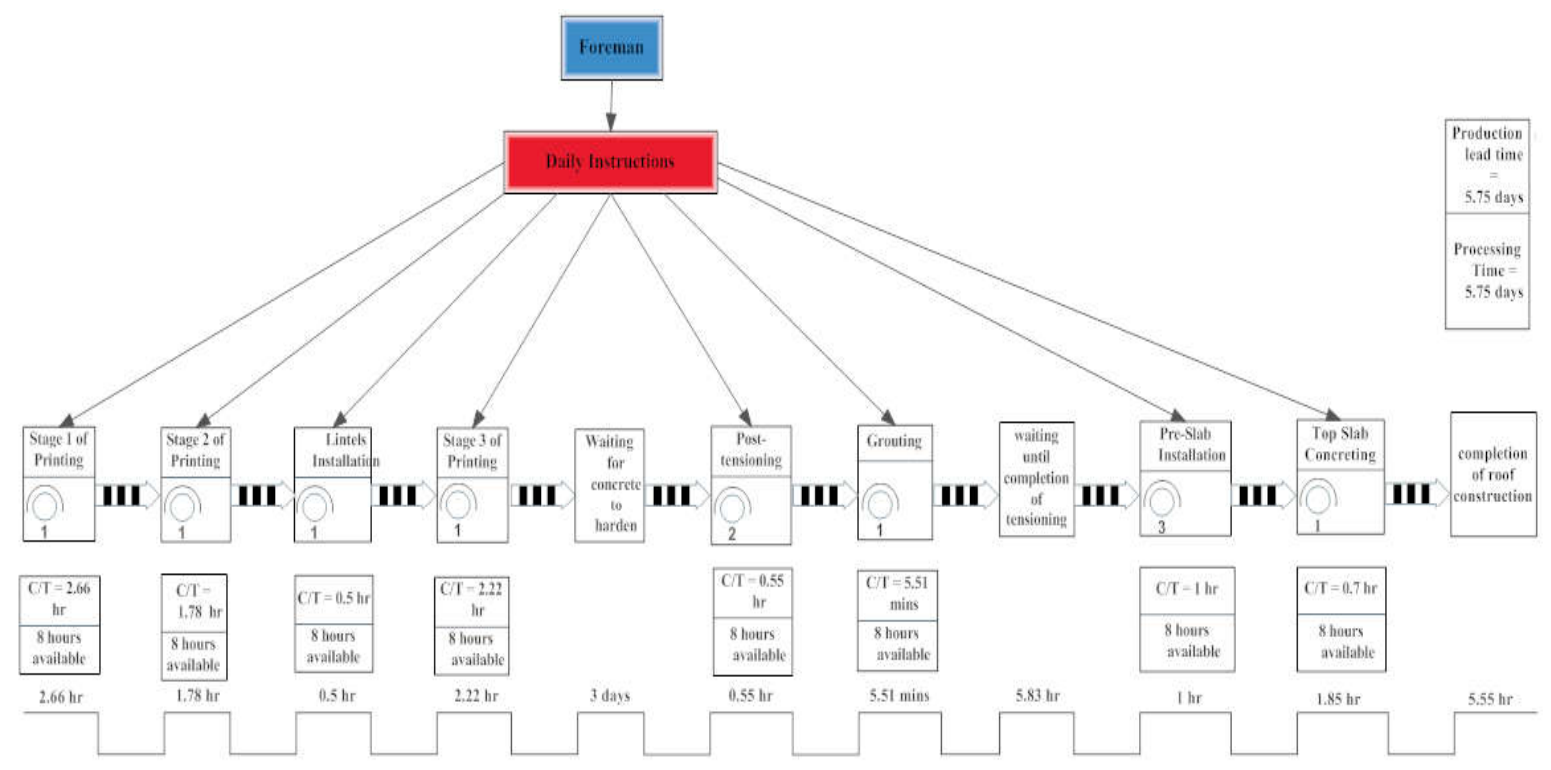

Figure 3. VSM for 3D concrete printing

\section{COMPARISON AND LEAN ANALYSIS}

The major lean enhancements that 3D concrete printing brings about are discussed in the following subsections.

\subsection{Lead Time}

The most noticeable improvement 3D concrete printing helps achieve relates to the delivery time of the house. It also occurs that such an improvement is deemed an essential goal in a lean environment (Liker 2004). Building the house using the conventional method takes around 15 days while 3D concrete printing requires only 6 days. Note that the latter duration can be further reduced if another reinforcement technique is to be used. Recall that 3 out of 6 days were allocated to allow concrete to harden before post-tensioning is done. Thus, a $60 \%$ reduction in the total construction duration is realized. This signifies a much faster response to the customer's needs.

\subsection{Waste}

Production lead time in the conventional method is greater than the actual processing time with approximately one-day difference. Note that this difference for such value stream maps depends on the selected unit of flow which in turn affects the quantity of inventory between subsequent processes. This unit was chosen, however, to be as close as possible to real life scenarios. Assuming similar conditions, this difference is eliminated in the $3 \mathrm{D}$ concrete printing technique resulting in a more lean process since inventory is classified as a major type of waste from a lean perspective.

Moreover, the conventional method of construction necessitates considerable movement of employees to transport materials and parts especially forms and the large number of steel bars in addition to all the necessary accessories. This transport of materials is considered waste and is greatly minimized/eliminated in the form-free construction, 3D concrete printing. 
Finally, 3D concrete printing eradicates another form of waste which consists of producing and, consequently, correcting defective parts. This is clarified in the following subsection.

\subsection{Jidoka and Quality}

It is good to first note that many concrete problems that usually occur in form construction such as honeycombing, airholes, sand streaks, segregation or others are avoided since no formwork is used. This results in producing much less defective work from the first place. One advantage of using 3D concrete printing resides in the fact that problems that might occur during concrete pouring are made visible. Such defects are usually hidden by forms and are only exposed after striping the forms. Repair and rework are then needed. In 3D concrete printing, any defect that occurs while extruding concrete filaments is easily spotted and, thus, can be directly treated before another layer is deposited. In fact, it is mandatory to stop and fix the problem because one defective layer at the bottom of a wall disrupts the pattern of all the subsequent layers. This fulfils the purpose of Jidoka which consists of never allowing a defect to pass to the next station (Liker 2004).

Therefore, 3D concrete printing enhances the quality of the final product as it imposes in-station quality control and facilitates error proofing. A better quality increases the product value in the eyes of the customer.

\subsection{Cost}

One advantage when it comes to 3D concrete printing is cost related. In fact, a Chinese company built ten houses in one day with a construction cost of approximately $4500 \$$ per house (Feng 2014). Many factors accompanying 3D concrete printing lead to a lower construction cost. To start with, 3D concrete printing necessitates much less labourers than conventional construction. For instance, one operator of the printer can replace all the labourers needed for shuttering and concrete works, a total of 8 workers in this study. Also, some materials as well as activities are not needed in 3D concrete printing; forms along with all their accessories are not used, vibrating concrete is not done, and some finishing operations are not needed. Not to forget that the construction duration is much shorter for 3D concrete printing. This results in a major cut down on overhead expenses in addition to labour and equipment costs. Finally, construction using 3D concrete printing requires less supervision as fewer labourers are involved in the process leading to an even lower cost. Nevertheless, it should be noted that the cost of 3D concrete printers is currently high. Thus, detailed studies will be later conducted to address return on investment analyses for 3D concrete printing.

\section{CONCLUSION}

A wide research aims at integrating the lean philosophy into the construction industry. The construction industry might seem very far from perfection from a lean perspective. Reducing cost and time is usually very challenging when it comes to construction. Quality improvement is easier but is mostly realized at the expense of cost and time. Yet introducing 3D printing to construction may tip the scales. It greatly serves the lean goals including time, cost, and quality. Production lead time could be reduced by up to $60 \%$ and even more if the process is better designed and optimized. Cost could be greatly reduced as less labourers, materials, and equipment are needed, less overhead expenses are spent, and less supervision is required. Finally, quality is improved due to a proactive 
rather than a reactive environment for treating defects. Moreover, the fact that construction using 3D concrete printing is much more automated than conventional construction implies less uncertainty in the system. Fluctuations in the construction process and human errors are set to a minimum. Hence, quality is significantly ameliorated. Therefore, 3D concrete printing brings a lot of value to the customer and, hence, helps approaching the lean ideal.

\section{REFERENCES}

American Polysteel. (2005). PS•3000 Installation Manual Step-by-Step Procedures. Retrieved January 13, 2017, from http://www.polysteel.com/

Bos, F., Wolfs, R., Ahmed, Z., \& Salet, T. (2016). Additive manufacturing of concrete in construction: potentials and challenges of $3 D$ concrete printing. Virtual and Physical Prototyping, 11(3), 209-225.

Edge, R. M. (2000). The effect of monetary policy on residential and structures investment under differential project planning and completion times. International Finance Working Paper, (671).

El Sakka, F., Eid, K., Narciss, T., \& Hamzeh, F. Integrating Lean into Modular Construction: A Detailed Case Study of Company X.

Feng, L. Y. (2014). Study on the Status Quo and Problems of 3D Printed Buildings in China. Global Journal of Human-Social Science Research, 14(5).

Hewitt, C. (Director). (2010, May 8). Why Design Now? Contour Crafting [Video file]. Retrieved January 13, 2017, from https://www.youtube.com/channel/UCBCaO28GYGr7IoKVjT4Jx5A

Hwang, D. O. O. I. L., \& Khoshnevis, B. (2005). An innovative construction processcontour crafting (CC). In 22nd International Symposium on Automation and Robotics in Construction (ISARC 2005), Ferrara, Italy.

Khoshnevis, B. (2004). Automated construction by contour crafting-related robotics and information technologies. Automation in construction, 13(1), 5-19.

Marchwinski, C., \& Shook, J. (2003). Lean lexicon: a graphical glossary for lean thinkers. Lean Enterprise Institute.

Malaeb, Z., Hachem, H., Tourbah, A., Maalouf, T., El Zarwi, N., \& Hamzeh, F. (2015). 3D Concrete Printing: Machine and Mix Design. International Journal of Civil Engineering, 6(6).

Labonnote, N., Rønnquist, A., Manum, B., \& Rüther, P. (2016). Additive construction: State-of-the-art, challenges and opportunities. Automation in Construction, 72, 347366.

Liker, J. K. (2004). The 14 principles of the Toyota way: an executive summary of the culture behind TPS. The Toyota Way, 14, 35-41.

Rother, M., \& Shook, J. (2003). Learning to see: value stream mapping to add value and eliminate muda. Lean Enterprise Institute. [1.3].

Rouhana, C.M., Aoun, M.S., Faek, F.S., Eljazzar, M.S., and Hamzeh, F.R. The Reduction of Construction Duration by Implementing Contour Crafting (3D Printing). 22nd Annual Conference of the International Group for Lean Construction. Oslo, Norway, 25-27 Jun 2014. pp 1031-1042

Whirlwind Team. (2016, March 30). Impacts of 3D Printing on the Construction Industry. Retrieved January 11, 2017, from http://www.whirlwindsteel.com/blog/impacts-of3d-printing-on-the-construction-industry 